\title{
Housing Situation, Residential Relationship And The Prevention Of Chronic Diseases Of The Elderly
}

\author{
Yajun Duan \\ Shanghai University of Engineering Sciences \\ Juan Luo ( $\nabla$ emmaluojuan@163.com ) \\ Shanghai University of Engineering Sciences
}

\section{Research Article}

Keywords: Elderly floating population, chronic diseases, housing supply, housing level, social security

Posted Date: June 14th, 2021

DOl: https://doi.org/10.21203/rs.3.rs-537516/v1

License: (c) (i) This work is licensed under a Creative Commons Attribution 4.0 International License. Read Full License 


\title{
Housing situation, residential Relationship and the prevention of chronic diseases of the elderly
}

\author{
Duan Yajun Luo Juan
}

Author unit: Shanghai University of

Engineering Science, Shanghai,China

Corresponding:emmaluojuan@163.com

Full list of author information is available at the end of the article

\begin{abstract}
:
Background:To understand the impact of housing and living-related factors on the chronic diseases of the elderly floating population, and to provide preventive measures for reducing the risk of chronic diseases among the elderly floating population in my country.
\end{abstract}

Methods:In this paper, we used the data from the 2017 Migrant Population Dynamic Monitoring Survey in China, selected housing and housing-related factors as explanatory variables, and adopted a binary logistic regression analysis method.

Result:People living in free housing are more mobile and more susceptible to chronic diseases; most people in self-owned housing need to repay their mortgages in their daily lives, and there is a certain life pressure that affects them to enjoy a high-quality life; elderly floating population who migrate with spouses or children Life pressure is heavier, and there is a greater probability 
of chronic disease risk.

Conclusion:This article proposes that all localities should strictly control housing prices, increase housing supply for the floating population, improve the service level of the elderly floating population, improve the social security system and mechanisms, and effectively improve the happiness of the elderly floating population.

Key words: Elderly floating population; chronic diseases; housing supply; housing level; social security 


\section{Introduction}

In recent years, the development trend of China's aging has become more and more serious. According to the "China Statistical Yearbook 2020", the number of elderly people in my country has exceeded 200 million by 2020, and the proportion has increased year by year. According to estimates, it is estimated that China will reach the "tenth During the Fourth Five-Year Plan period, it will move from a mildly aging society to a moderately aging society. At the same time, the scale of my country's floating population has reached 300 million, accounting for $18 \%$ of the total, which shows that its number cannot be underestimated. The elderly floating population has the two major characteristics of "old age" and "mobile", which is a weakness in the public service system. According to the National Health and Family Planning Commission's special survey of mobile elderly health services, the current elderly mobile population accounts for the total number of floating populations. $7.2 \%$. With the development of society, not only can we not ignore the elderly migrant population, we should also make reasonable judgments and plans for them, especially in terms of housing, living standards, and social security to ensure their basic lives. Judging from the reality, the elderly migrants leave their hometowns and live and work in unfamiliar cities. Housing and living standards are related to their long-term stay, which is a key factor in determining urban integration. At the same time, the elderly who are far away from their hometowns have various problems such as transfer and continuity in social security. Whether it indirectly affects health problems is also a key issue that the society has been paying attention to and solving. Therefore, studying the impact of housing and living factors on the chronic diseases of the elderly floating population. It is of great significance to how China will deal with the aging problem in the future and promote the development of public health services for the floating population.

\section{Literature review}

At present, many domestic and foreign studies on housing, residence, and chronic diseases of the elderly floating population provide a reference for the development of this article.

According to the report on "Elderly Refugees and Refugee Health" issued by the World Health Organization in 2018, aging and mobility are themselves a complex and multi-dimensional process, determined by various factors in a person's life, and the whole of Europe is aging. The main trend of development is caused by the continued low birth rate and increased life expectancy ${ }^{[1]}$ (WHO Regional Office for Europe, 2018). It can be seen that the problem of aging has become a common problem in the world. It is challenging the knowledge research of scholars all over the world, and it is also challenging to continue to formulate and improve policies and practices regarding the health of elderly refugees and immigrants. Jane M. Cramm and Anna P. Nieboer (2018) investigated the health problems of Turks who immigrated to 
Rotterdam, and found that the satisfaction of the elderly after immigrants in their lives has a significant impact on the health of the elderly and gets along with their families. Harmonious elderly people live longer ${ }^{[2]}$. Laura Corneliusson, Anders Sköldunger, et al (2019) explored the health status of all elderly floating population living in free housing in Sweden, and the results showed that the health level of elderly floating population living in free housing is lower than that of the elderly in self-owned housing. The government should try its best to meet the environmental and social needs of such people and solve their potential physical needs ${ }^{[3]}$.

The current academic standards for evaluating population health include self-evaluation of health, chronic diseases, and activities of daily living (ADL, IADL) [20]. Most domestic research on the factors affecting the health of the elderly floating population is about self-evaluation of health. Regarding chronic diseases. Xie Jin et al. (2020) studied the impact of the city itself on the health of the elderly population, and proposed that migrants with a high degree of education have a higher risk of chronic diseases, while married life does not have a positive effect on health, and mobility with peers may also cause the elderly to suffer. For chronic diseases, it is recommended to expand the coverage of health records and strengthen the elderly's awareness of chronic diseases ${ }^{[6]}$. Wu Yu et al. (2020) explored the health of the elderly floating population and its influencing factors from the dual perspectives of age and mobility characteristics, and found that women, the elderly, the rural, and the elderly with frequent mobility have poor health conditions and higher risk of chronic diseases. The state should give priority Concern and policy preference ${ }^{[7]}$. Liu Tingting et al. (2014) conducted a questionnaire survey on the floating population in various districts and counties of Shanghai. The research and analysis showed that the characteristics of Shanghai's floating population's household migration are mainly rented housing, and the increase in the household migration population will increase the probability of owning their own housing. The social stratification caused by the different qualities of the floating population also affects housing choices to a certain extent. Therefore, the government should gradually liberalize the urban household registration system and improve the quality of the floating population ${ }^{[8]}$.

From the perspective of research objects, foreign research on the physical fitness of the elderly floating population has reached a relatively mature stage. In contrast, domestic research on the health of the elderly floating population is still relatively small, and in the past it was based on family economic reasons, general social status, Researches on supporting services and other aspects are focused more on the impact of environmental changes on the health of the elderly floating population. There is no targeted study on the impact of chronic diseases in these groups, and there are fewer studies combining their housing and living conditions with chronic diseases. It's so few. Based on this, this article is based on the 2017 National Floating Population Health and Family Planning Survey Data, and explores the impact of housing factors and housing factors on the chronic diseases of the elderly floating population. Through empirical analysis, further conclusions are drawn for subsequent recommendations. Effective measures that can specifically improve the housing quality of the elderly floating population and improve life and health provide a solid 
foundation.

\section{Research hypothesis}

At present, the situation of chronic diseases among the elderly floating population in my country is deteriorating. According to investigations and studies, at least one third of the elderly are suffering from chronic diseases. At the same time, the total number of chronic diseases is increasing year by year, and the age of the disease is also increasing. Younger development ${ }^{[11]}$. The housing properties of the floating population are diverse, but in contrast, the housing level is relatively low, and the proportion of people who can own a house on their own is even rarer. As modern social economic activities become more complex and changeable, housing prices are rising year by year. For those residents who rent other people's houses to meet their housing needs, the rent they pay is the cost of residential services ${ }^{[9]}$. The higher the rent, the higher the housing services. In contrast, the elderly floating population living in free housing has no rent or mortgage pressure. Such people may use the money for children's education, travel, and maintaining good interpersonal relationships to improve their quality of life. In terms of matters, the elderly can obtain personalized emotional needs, enhance their sense of life security and confidence in the future, reduce depression and other bad mental states, and enjoy their old age ${ }^{[10]}$, while the elderly floating population with self-owned housing has a stable life, but You may need to repay your mortgage. Based on this, this article puts forward the first research hypothesis:

Hypothesis 1: Compared with rented housing, the elderly floating population with self-owned housing is more likely to suffer from chronic diseases.

As a necessities of human life, housing has become a part of survival, and it can directly reflect people's living standards and quality of life. For the floating population, some people have little or no savings due to unstable work or low income, so it is difficult to rent high-quality houses on the market or directly buy houses, sometimes with the change of working place. Choose short-term rental housing, thus becoming a new housing difficulty group in the city ${ }^{[19]}$. Nowadays, housing prices are still in the stage of continuous rise. Even if the government intervenes in macro-control through some means, it still cannot resist the upward trend. However, the increase in house prices will inevitably lead to an increase in rents for renting houses, which affects each other, and is a huge challenge for the unstable floating population. For the elderly floating population, with the increase of age, the physiological functions of the elderly will gradually degrade, such as the decline in audiovisual, memory and walking ability, and even some simple daily activities are difficult to complete ${ }^{[20]}$, plus The pressure of rent will force the elderly to look for work to make ends meet, causing both physical and psychological pressure. We believe that the increase in rent pressure will put more pressure on the elderly and their children. When they cannot fully enjoy the services and care of the society, they will increase the risk of illness. Based on this, this article puts forward a second research hypothesis:

Hypothesis 2: The higher the housing rent, the greater the probability of chronic 
diseases among the elderly floating population.

At present, the housing choices of the elderly floating population in China have been diversified. The proportion of the elderly who choose to live alone is increasing. The elderly believe that living alone can reduce the life pressure of their children when they are still in good physical condition. However, some survey data show that most elderly people still want to live with their spouses and children. The "Elderly Care and Public Policy" survey carried out in 2014 also shows that although $70 \%$ of the respondents indicated that they would like to live with their spouses and children. Live with parents. But $80 \%$ of the elderly really want to live a carefree life when they are in good health. Among them, 53.4\% of the respondents said that if they can live on their own, they are more willing to choose a partner than with their children. Living and living together can get a greater sense of happiness, but you don't want to be too far away from your children, that is, you only need to keep "a bowl of soup". Only a small number of people express a strong desire to live with their children. And there have been studies showing that the health of the elderly is inversely proportional to the willingness of the elderly to live with their children. The living arrangement has a significant impact on the quality of life, mental status, and mental health of the elderly floating population ${ }^{[17]}$. People's quality of life is relatively poor, and mental pressure is greater. Based on this, this article puts forward a third research hypothesis: Hypothesis 3: Compared with living alone, elderly migrants living with their families are more likely to suffer from chronic diseases.

The physical and mental health of the elderly and their ability to take care of themselves limit whether the elderly are willing to live with other people. When they enter old age, their self-care ability and health level will gradually decline, and they need family members to accompany and take care of them in their daily lives. Therefore, having several family members living together will be more conducive to improving the material and spiritual living standards of the elderly in their later years. For the elderly floating population, if they leave their hometown to a new city, there are many cases where the family moves, and there will be a situation where there are more than three people living together. However, when there are too many people living together, the older the elderly have to take care of more family members and their lives become more restrictive. They not only have to take care of the daily affairs of the family, but also the daily life of the next generation of grandchildren, which will affect the physical and mental health of the elderly floating population over time. It has an impact and increases the probability of them suffering from chronic diseases. Compared with living with a spouse or a child, the elderly can live more relaxed and relaxed lives. Based on this, this article proposes a fourth research hypothesis:

Hypothesis 4: The greater the number of people living together, the greater the probability that the elderly floating population suffers from chronic diseases.

\section{Research design}

\subsection{Data source}

This study uses data from the "the 2017 Migrant Population Dynamic Monitoring 
Survey in China"1. This survey is a one-box sample survey of the floating population in 31 provinces (autonomous regions, municipalities) and Xinjiang Production and Construction Corps. Since 2009 Ten surveys have been carried out since the beginning of the year, mainly adopting a stratified, multi-stage, and PPS method[7] to survey men and women who have lived in the local area for more than one month and who are not registered in the district (county, city). The effective sample size is 169,989 persons, of which the sample size of the migrant population aged 60 and above is 9,218 persons. The survey and monitoring content includes basic information of migrant individuals and their families, mobility status and willingness to stay, health and public services, and social integration., Can fully meet the needs of this research.

\subsection{Model selection}

Logistic regression models, Probit regression models, and negative binomial distribution models are commonly used in academic research on health influencing factors. Since the main variable of this study is the prevalence of chronic diseases in the elderly floating population, the results are sick and not sick., Is a binary variable, therefore, a binary logistic regression model is selected, which is expressed as:

$$
\ln \left(\frac{\mathrm{p}(Y=1 \mid X)}{1-p(Y=1 \mid X)}=\beta_{0}+\beta_{1} X_{1}+\beta_{2} X_{2}+\beta_{3} X_{3}+\cdots \beta_{K} X_{K}\right.
$$

Among them, $\ln \left(\frac{\mathrm{p}(Y=1 \mid X)}{1-p(Y=1 \mid X)}\right.$ represents the dependent variable, which is a binary variable, $\mathrm{Xi}$ is the independent variable, $\beta \mathrm{i}$ represents the average effect of each unit change in $\mathrm{Xi}$ on the dependent variable when other independent variables remain unchanged, and $\beta 0$ is the intercept term.

\subsection{Variable selection}

\subsubsection{Interpreted variables}

Chronic diseases have always been a hot issue in the academic community. The prevalence of chronic diseases can reflect the physical health of the surveyed population, and also serves as an important reference for rational planning of the national health system. Therefore, this article chooses the rate of chronic diseases as the explanatory variable to examine the health status of the elderly floating population. According to the questionnaire question "Are you suffering from high blood pressure or type 2 diabetes diagnosed by a doctor?", the answers are divided into two categories, and the answers are "Have high blood pressure", "Have diabetes", "Both of them" It is classified as "yes" and assigned a value of 1; the answers to "all suffering" and "not seen" are classified as "no" and assigned a value of 0 .

\subsubsection{Explaining variables}

According to the research content of this article and the summary of the existing

\footnotetext{
1 " National Floating Population Health and Family Planning Dynamic Monitoring Survey " is the data-set publicly available.
} 
literature, this study divides the explanatory variables into two categories: housing factors and housing factors: the first type of housing factors, mainly including the nature of housing and housing expenditure, will answer the questionnaire "unit /Employer's room (excluding employment sites)", "Government-provided public rental housing", "Private renting-whole rental", "Private renting-Shared renting" are classified as rented housing, answer "borrowed housing", "employment place", "Other informal residences" are classified as free housing, and "self-purchasing commercial housing", "self-purchasing affordable housing", "self-purchasing small-property housing", and "self-built housing" are classified as self-owned housing, and housing expenditures are classified according to the respondent The amount filled in is divided into three gradients. The answer with a rent of 0 is defined as no rent, the answer with housing expenditure within 3000 is defined as low rent, and the answer with more than 3000 yuan is defined as high rent; the second type of housing factors mainly includes Residential arrangements and co-resident population are divided into living alone, living with spouse, living with spouse and children, and others. "Others" includes options other than the above three types of residence. The number of co-residents is divided into 2 or less , 3-5 people, 6 people and above, assign 1, 2, and 3 respectively.

\subsubsection{Control variables}

According to research needs, this article selects the age, gender, marital status, education level, and mobility range of the elderly as control variables. On the whole, the surveyed elderly floating population group is not very old, with an average age of 67.5 years. Therefore, the age is divided into three groups: 60-64 years old, 65-69 years old, 70 years old and above; in marital status, Unmarried, divorced, widowed, and cohabitation are regarded as not married and assigned a value of 0 ; first marriage and remarriage are regarded as married and assigned a value of 1 . See Table 1 for other specific assignments.

Table1 Descriptive statistics of variables

$\mathrm{N}=9218$

\begin{tabular}{|c|c|c|c|c|c|}
\hline \multicolumn{2}{|c|}{ variable } & Assignment & $\begin{array}{c}\text { percentage } \\
(\%)\end{array}$ & $\begin{array}{l}\text { average } \\
\text { value }\end{array}$ & $\begin{array}{l}\text { Standard } \\
\text { deviation }\end{array}$ \\
\hline $\begin{array}{c}\text { Dependent } \\
\text { variable }\end{array}$ & $\begin{array}{c}\text { Prevalence } \\
\text { of chronic } \\
\text { diseases } \\
\end{array}$ & $\begin{array}{l}1=\text { Yes } \\
0=\text { No }\end{array}$ & $\begin{array}{l}31.37 \\
68.63\end{array}$ & 0.31 & 0.464 \\
\hline \multirow{3}{*}{$\begin{array}{l}\text { Independe } \\
\text { nt variable }\end{array}$} & $\begin{array}{l}\text { Housing } \\
\text { nature }\end{array}$ & $\begin{array}{c}1=\text { Renting } \\
2=\text { Free } \\
3=\text { Owned }\end{array}$ & $\begin{array}{l}42.15 \\
8.25 \\
49.60\end{array}$ & 2.07 & 0.955 \\
\hline & $\begin{array}{c}\text { Housing } \\
\text { expenditure }\end{array}$ & $\begin{array}{c}1=\text { No rent } \\
2=\text { Low rent } \\
3=\text { High rent }\end{array}$ & $\begin{array}{l}51.30 \\
44.76 \\
3.94\end{array}$ & 1.53 & 0.573 \\
\hline & $\begin{array}{l}\text { Residence } \\
\text { arrangement } \\
\mathrm{S}\end{array}$ & $\begin{array}{c}1=\text { Alone } \\
2=\text { With spouse } \\
3=\text { With spouse and }\end{array}$ & $\begin{array}{l}19.47 \\
25.98 \\
39.45\end{array}$ & 2.24 & 1.001 \\
\hline
\end{tabular}




\begin{tabular}{|c|c|c|c|c|c|}
\hline & & $\begin{array}{l}\text { children } \\
4=\text { others }\end{array}$ & 15.10 & & \\
\hline & $\begin{array}{l}\text { Resident } \\
\text { population }\end{array}$ & $\begin{array}{l}1=\text { Less than } 2 \\
\quad 2=3-5 \\
3=\text { More than } 6\end{array}$ & $\begin{array}{c}58.43 \\
35.34 \\
6.23\end{array}$ & 1.48 & 0.612 \\
\hline \multirow{5}{*}{$\begin{array}{c}\text { Control } \\
\text { variable }\end{array}$} & Age & $\begin{array}{c}1=60-64 \\
2=65-69 \\
3=\text { More than } 70\end{array}$ & $\begin{array}{l}37.75 \\
32.75 \\
29.50\end{array}$ & 1.92 & 0.816 \\
\hline & Gender & $\begin{array}{c}0=\text { Male } \\
1=\text { Female }\end{array}$ & $\begin{array}{l}58.78 \\
41.22\end{array}$ & 0.41 & 0.492 \\
\hline & $\begin{array}{c}\text { Marital } \\
\text { status }\end{array}$ & $\begin{array}{c}0=\text { Not married } \\
1=\text { Married }\end{array}$ & $\begin{array}{l}14.48 \\
85.52\end{array}$ & 0.86 & 0.352 \\
\hline & $\begin{array}{c}\text { Education } \\
\text { level }\end{array}$ & $\begin{array}{c}1=\text { Elementary school } \\
\text { and below } \\
2=\text { junior high school } \\
3=\text { High school or } \\
\text { technical secondary } \\
\text { school } \\
4=\text { College degree and } \\
\text { above }\end{array}$ & $\begin{array}{l}32.14 \\
17.78 \\
5.63\end{array}$ & 1.85 & 0.908 \\
\hline & Flow range & $\begin{array}{c}\text { 1=Inter-county } \\
2=\text { Inter-city } \\
3=\text { Inter-province }\end{array}$ & $\begin{array}{l}20.28 \\
34.53 \\
45.19\end{array}$ & 2.25 & 0.770 \\
\hline
\end{tabular}

\section{Data analysis results}

5.1 Statistical analysis results

According to the descriptive statistics of the variables, this article further makes a statistical test of the explanatory variables on chronic diseases, and calculates the percentages of housing factors and housing factors with and without chronic diseases. The specific percentages of people are shown in the table 2.

Table 2 Univariate analysis of explanatory variables

\begin{tabular}{cccccc}
\hline & & \multicolumn{3}{c}{ Prevalence of chronic diseases } \\
\multirow{2}{*}{ Independent variable } & \multicolumn{2}{c}{ Yes $(\mathrm{N}=2892)$} & \multicolumn{2}{c}{ No $(\mathrm{N}=6326)$} \\
& & Number & $\%$ & Number & $\%$ \\
\hline \multirow{2}{*}{$\begin{array}{c}\text { Housing } \\
\text { nature }\end{array}$} & Renting & 1008 & 34.85 & 2877 & 45.48 \\
& Free & 244 & 8.44 & 517 & 8.17 \\
& Owned & 1640 & 56.71 & 2932 & 46.35 \\
\hline
\end{tabular}




\begin{tabular}{cccccc}
\hline \multirow{2}{*}{ Housing } & No rent & 1622 & 48.89 & 3107 & 52.40 \\
expenditure & Low rent & 1143 & 45.44 & 2983 & 44.45 \\
& High rent & 127 & 5.67 & 236 & 3.15 \\
& Alone & 659 & 22.79 & 1731 & 27.44 \\
Residence & With spouse & 1205 & 41.70 & 2425 & 38.41 \\
arrangements & With spouse & 613 & 21.13 & 1196 & 18.72 \\
& and children & & 14.38 & 974 & 15.43 \\
& others & 415 & 54.18 & 3644 & 60.37 \\
Resident & Less than 2 & 1742 & 38.45 & 2285 & 33.92 \\
population & $3-5$ & 973 & 7.37 & 397 & 5.71 \\
\hline
\end{tabular}

According to the statistical results of the explanatory variables, a horizontal comparison shows that in terms of housing factors, the elderly floating population living in rented housing has a lower probability of suffering from chronic diseases, and living in free housing has little effect on the prevalence of chronic diseases. The elderly in self-owned housing It is more likely to suffer from chronic diseases, which is consistent with hypothesis one. Elderly people without rent are less likely to get sick. The higher the rent, the greater the probability of getting sick than the probability of not getting sick, which is consistent with Hypothesis 2. In terms of housing factors, the percentage of sickness living with spouse and with spouse and children is higher. The percentage of people living alone who are not sick is greater, which is in line with the hypothesis 3 . When more than three people live together, the risk of illness increases, which is consistent with Hypothesis 4.

Longitudinal comparative analysis shows that with the development of society, more and more elderly migrants tend to buy houses, and the demand for housing increases. Most people choose low rents and pursue cost-effectiveness in renting houses. This shows that control Housing rent is imperative. At present, the family-style multi-person residence is no longer popular. Modern people pay more attention to privacy protection, and the phenomenon of living alone is more common. How to improve the quality of housing has become a topic of more concern for the floating population, and it is also a problem worthy of consideration by the entire society.

\subsection{Regression analysis results}

According to the above analysis model, this paper uses SPSS software to conduct binary Logit regression analysis on related data, and establish four models respectively. Model 1 only included control variables; Model 2 only included housing-related factors in addition to control variables, namely housing properties and housing expenditure; Model 3 included only housing-related factors in addition to control variables, namely Living arrangements and the number of people living together; Model 4 is a full-sample model, which comprehensively considers the influence of control variable factors, housing-related factors, and housing-related 
factors on the prevalence of chronic diseases in the elderly floating population. According to the results of Model 4, the effects of the two factors of housing and residence are roughly similar to those of the previous three models, indicating that the effects of these variables on the chronic diseases of the elderly floating population have a certain degree of stability. Table 3 shows the regression results of different models.

Table 3 Logit regression of the impact of housing-living factors on the chronic diseases of the elderly floating population

\begin{tabular}{|c|c|c|c|c|}
\hline Variable & Model 1 & $\begin{array}{l}\text { Model } 2 \\
\text { (housing) }\end{array}$ & Model 3 (living) & $\begin{array}{c}\text { Model } 4 \\
\text { (housing+living) }\end{array}$ \\
\hline \multirow[t]{2}{*}{ Gender (male) } & 1.296 & 1.258 & 1.274 & 1.241 \\
\hline & $(0.259)^{* * *}$ & $(0.229)^{* * *}$ & $(0.242)^{* * *}$ & $(0.216)^{* * *}$ \\
\hline \multirow{2}{*}{$\begin{array}{l}\text { Marital status ( Not } \\
\text { married) }\end{array}$} & 1.229 & 1.197 & 1.139 & 1.128 \\
\hline & $(0.206)^{* * *}$ & $(0.180)^{* * *}$ & $(0.130)^{*}$ & $(0.121)$ \\
\hline \multicolumn{5}{|c|}{ Education level (Elementary school and below) } \\
\hline \multirow[t]{2}{*}{ junior high school } & 1.005 & 0.988 & 1.010 & 0.990 \\
\hline & $(0.005)$ & $(-0.012)$ & $(0.010)$ & $(-0.010)$ \\
\hline \multirow{2}{*}{$\begin{array}{l}\text { High school or } \\
\text { technical secondary } \\
\text { school }\end{array}$} & 1.077 & 1.024 & 1.086 & 1.031 \\
\hline & $(0.074)$ & $(0.024)$ & $(0.083)$ & $(0.031)$ \\
\hline \multirow{2}{*}{$\begin{array}{l}\text { College degree and } \\
\text { above }\end{array}$} & 1.311 & 1.211 & 1.335 & 1.227 \\
\hline & $(0.271)^{* * *}$ & $(0.191)^{*}$ & $(0.289)^{* * *}$ & $(0.204)^{* *}$ \\
\hline \multicolumn{5}{|c|}{ Flow range (Inter-county) } \\
\hline \multirow[t]{2}{*}{ Inter-city } & 0.880 & 0.882 & 0.883 & 0.887 \\
\hline & $(-0.128)^{* *}$ & $(-0.126)^{* *}$ & $(-0.124)^{* *}$ & $(-0.120)^{*}$ \\
\hline \multirow[t]{2}{*}{ Inter-province } & 0.816 & 0.831 & 0.831 & 0.956 \\
\hline & $(-0.203)^{* * *}$ & $(-0.185)^{* * *}$ & $(-0.185)^{* * *}$ & $(-0.168)^{* * *}$ \\
\hline \multicolumn{5}{|l|}{ Age（60-64） } \\
\hline \multirow[t]{2}{*}{$65-69$} & 1.429 & 1.378 & 1.421 & 1.372 \\
\hline & $(0.357)^{* * *}$ & $(0.321)^{* * *}$ & $(0.351)^{* * *}$ & $(0.316)^{* * *}$ \\
\hline \multirow[t]{2}{*}{ More than 70} & 2.447 & 2.287 & 2.480 & 2.257 \\
\hline & $(0.895)^{* * *}$ & $(0.827)^{* * *}$ & $(0.879)^{* * *}$ & $(0.814)^{* * *}$ \\
\hline \multicolumn{5}{|c|}{ Housing nature (Renting) } \\
\hline \multirow[t]{2}{*}{ Free } & & 1.184 & & 1.184 \\
\hline & & $(0.169)^{*}$ & & $(0.169)^{*}$ \\
\hline \multirow[t]{2}{*}{ Owned } & & 1.362 & & 1.362 \\
\hline & & $(0.309)^{* * *}$ & & $(0.309)^{* * *}$ \\
\hline \multicolumn{5}{|c|}{ Housing expenditure (No rent) } \\
\hline \multirow[t]{2}{*}{ Low rent } & & 1.062 & & 1.077 \\
\hline & & $(0.060)$ & & $(0.074)$ \\
\hline High rent & & 1.162 & & 1.207 \\
\hline
\end{tabular}




\begin{tabular}{|c|c|c|c|c|}
\hline & & $(0.150)$ & & $(0.188)$ \\
\hline \multicolumn{5}{|c|}{ Residence arrangements (Alone) } \\
\hline \multirow[t]{2}{*}{ With spouse } & & & 1.153 & 1.126 \\
\hline & & & $(0.142)^{* *}$ & $(0.119)^{*}$ \\
\hline \multirow{2}{*}{$\begin{array}{l}\text { With spouse and } \\
\text { children }\end{array}$} & & & 1.280 & 1.235 \\
\hline & & & $(0.247)^{* * *}$ & $(0.211)^{* * *}$ \\
\hline \multirow[t]{2}{*}{ others } & & & 1.084 & 1.076 \\
\hline & & & $(0.081)$ & $(0.073)$ \\
\hline \multicolumn{5}{|c|}{ Resident population (Less than 2) } \\
\hline \multirow[t]{2}{*}{$3-5$} & & & 0.945 & 0.918 \\
\hline & & & $(-0.056)$ & $(-0.086)$ \\
\hline \multirow[t]{2}{*}{ More than 6} & & & 0.949 & 0.899 \\
\hline & & & $(-0.053)$ & $(-0.106)$ \\
\hline Log likelihood ratio & 11156.732 & 11126.417 & 11143.387 & 11114.611 \\
\hline $\begin{array}{l}\text { Cox\&Snell R } \\
\text { Square }\end{array}$ & 0.033 & 0.036 & 0.035 & 0.038 \\
\hline $\begin{array}{l}\text { Nagelkerke R } \\
\text { Square }\end{array}$ & 0.047 & 0.051 & 0.049 & 0.053 \\
\hline
\end{tabular}

Note: $* * *, * * *$ represent significant at the $10 \%, 5 \%$, and $1 \%$ significance levels, respectively; the reference group is in parentheses.

Gender, age, education level, marital status and migration scope have a significant impact on the chronic diseases of the elderly floating population

Model 1 mainly examines the influence of control variables on the chronic diseases of the elderly floating population. From the test results of the model, several variables such as gender, age, education level, marital status and mobility range have all passed the significance test.

From the perspective of gender structure, the prevalence of female elderly floating population is 1.296 times higher than that of males, indicating that among the elderly floating population, women may be more likely to suffer from chronic diseases than men under pressure from society, work, and family; from marital status From the above point of view, the regression coefficient of the elderly floating population in the marriage stage is $0.206(\mathrm{P}<0.01)$, indicating that the elderly in the marriage stage may also bear family burdens in addition to their own factors, so they are more important than those who are not married. Prone to chronic diseases.

As the age increases, the risk of chronic diseases among the elderly floating population also increases. Compared with the elderly in the 60-64 age group, the regression coefficients of the elderly in the 65-69 and 70-year-old and above age groups are $0.357(\mathrm{P}<0.01)$ and $0.895(\mathrm{P}<0.01)$, respectively, which shows that The probability of the elderly floating population suffering from chronic diseases is increasing with the increase of age, especially the elderly over 70 years old should have regular physical examinations to prevent the occurrence of chronic diseases such as hypertension and diabetes.

Through research and testing in terms of education level, compared with the elderly 
floating population with lower educational background, the regression coefficients of the elderly with a college degree or above are $0.271(\mathrm{P}<0.01)$, and the elderly with a college degree or below are not significant. The data reveals that as the level of education increases, the working pressure of the elderly migrant population is heavier, and there is a greater risk of chronic diseases. Therefore, it is necessary to pay attention to the combination of work and rest after work.

The reason why the floating population is called this way is that it is inevitable that it is mobile. Compared with intra-city inter-county mobility, the regression coefficients of intra-provincial inter-city mobility and inter-provincial mobility are $-0.128(\mathrm{P}<0.05)$ and $-0.203(\mathrm{P}<0.01)$, and the significance gradually increases. The living standards of cities in China have improved, food, clothing, housing and transportation are superior to small cities in all aspects, and medical equipment and services are more complete, so the risk of chronic diseases is also greatly reduced.

The nature of housing has a significant impact on the chronic disease part of the elderly floating population, and the housing expenditure has no significant impact

Model 2 mainly examines the impact of housing nature and housing expenditure on chronic diseases among the elderly floating population. Judging from the test results, the nature of housing has passed the significance test, and housing expenditure is not significant.

From the perspective of the nature of housing, free housing has a significant impact on the chronic diseases of the elderly floating population, while the impact of self-owned housing is significant under $1 \%$ statistical test, and the coefficient of free housing (0.169) is smaller than the coefficient of self-owned housing (0.309), indicating The elderly migrants who own their own houses and live in free housing are more likely to suffer from chronic diseases than those who rent housing, and compared with free housing, the elderly who live in self-owned housing are more likely to suffer from chronic diseases. This may be because the elderly who own houses are more stressed when they are young, and they may also have to pay back their mortgages and have greater mental stress. Therefore, the risk of chronic diseases in this group of people is greatly increased, thus verifying Hypothesis 1.

From the perspective of housing expenditure, the regression coefficient of the low-rent elderly floating population suffering from chronic diseases is 0.060 (not significant), and the regression coefficient of the high-rent elderly floating population is 0.150 (not significant), so it is impossible to prove that housing expenditure and elderly floating population suffer from chronic diseases There is a direct relationship, and hypothesis two cannot be verified.

The housing arrangement has a significant impact on the chronic diseases of the elderly floating population, and the impact on the co-resident population is not significant.

Model 3 mainly examines the impact of living arrangements and co-living population on the chronic diseases of the elderly floating population. From the test results, the housing arrangement has a significant impact on the chronic disease part of the elderly floating population, but the number of co-residents has no impact.

Different living arrangements have different effects on the elderly suffering from 
chronic diseases. From the regression data results, compared with living alone, living with a spouse below $5 \%$ has a significant impact. Living with a spouse and children has a significant impact on the chronic disease of the elderly floating population at the $1 \%$ statistical test level. Living with a person has no significant impact. Living with a spouse and children is more significant than living with a spouse, indicating that the elderly who live with their spouse and children get along with more family members and bear greater pressure, not just taking care of their own daily lives. They also have to worry about their children's lives, as the burden increases and they are more likely to suffer from chronic diseases, so Hypothesis 3 has been tested.

From the regression analysis results alone, the number of co-residents has no significant impact on the chronic diseases of the elderly floating population, and hypothesis 4 cannot be verified.

Housing factors have a greater impact on the chronic diseases of the elderly floating population than housing factors

Comparing Model 4 with other models, it can be seen that when housing and housing factors are added as independent variables, the influence of marital status on the chronic diseases of the elderly floating population weakens or even becomes insignificant. The significant impact of education level is when the housing factor is added. It is also significantly reduced afterwards. When housing factors are added, there is no significant impact on the nature of housing, and the correlation remains the same; but after housing factors are added, the impact of housing factors on the chronic diseases of the elderly floating population is also significantly reduced. It can be seen that the current The housing pressure of the elderly floating population is heavier and the impact on their own health is greater. This enlightens us to pay more attention to the housing problem of the floating population, moderately increase government intervention, and solve the problem of floating population living in different places to the greatest extent. At the same time improve the quality of life.

\section{Conclusions and recommendations}

Through descriptive statistical analysis of variables and the construction of a binary logistic regression equation, this paper focuses on the impact of housing factors and housing factors on the chronic diseases of the elderly floating population, and analyzes housing types, housing expenditures, housing arrangements, and co-living population. The effects and impacts of these aspects on the chronic diseases of the elderly floating population are different. This article mainly draws the following conclusions:

First, the average age of the elderly floating population in China is 67.5 years old. Among them, the number of males is larger than that of females, and the education level is generally lower. Nearly half of the elderly floating population has an education level of elementary school or below, and more than $80 \%$ of the elderly floating population are married. . In order to pursue a higher standard of living and quality, most elderly people choose to move on a large scale and move with their families. 
Second, among the surveyed subjects, the elderly floating population suffering from chronic diseases accounted for $30 \%$. The chronic disease problems of the elderly floating population are mainly characterized by the following categories: (1) Women. Women are already in a disadvantaged position in society, but under the status of "old age", their disadvantaged position is even more prominent. Women are under pressure from various sources of society and are more susceptible to chronic diseases. (2) In marriage. The analysis of the results shows that married life has a negative effect on the elderly floating population. Marriage means responsibility, and responsibility represents pressure. The elderly who are in marriage bear not only social pressure, but also family burden, and their risk of chronic diseases. greatly increase. (3) Highly educated. The elderly with a high degree of education know more about general health knowledge, and can basically learn related disease knowledge from scientific channels. However, these people often adopt self-diagnosis and self-medication methods when facing minor diseases. Sometimes self-diagnosis can delay the disease. Correct judgment and the best treatment period will eventually develop into a chronic disease. (4) Small-scale flow. The medical conditions in county towns are generally lower than those in provincial cities, which determines to a large extent that elderly people who migrate in a small area are prone to chronic diseases.

Third, the nature of housing has a significant impact on the chronic diseases of the elderly floating population. The housing arrangement has a significant impact on part of it, and the housing expenditure and the co-living population have no significant impact. Many people living in free housing have poor quality of life, unstable work and high mobility. The reality of this group of people requires the government and society to improve housing quality and control housing prices in a targeted manner; self-owned housing people are in their daily lives Most of them need to repay their mortgages, and there is a certain amount of life pressure that affects them to enjoy a high-quality life. How to improve the housing affordability of the migrants is worthy of extensive discussion and in-depth study; the elderly migrants who migrate with their spouses or children do more in their daily lives Although there is a certain sense of belonging and dependence psychologically, the living expenses are greater than that of the elderly living alone, life pressure is heavier, and there is a greater probability of chronic disease risk. 


\section{DECLARATIONS}

\section{Ethics approval and consent to participate}

Not applicable

\section{Consent for publication}

Not applicable

\section{Availability of data and materials}

"the 2017 Migrant Population Dynamic Monitoring Survey in China" is the data-set publicly available.The data set used in the current study can be obtained from public data according to reasonable requirements (https://chinaldrk.org.cn/wjw/\#/data/classify/population/yearList）.

\section{Competing interests}

The authors declare that they have no competing interests.

\section{Funding}

This study was funded by General Project of National Social Science Fund: Research on the Theory, Path and Practice Model of Healthy China Construction under Grant Number 20BJY014.

\section{Authors' contributions}

Duan Yajun and Luo Juan wrote the main manuscript text, All authors reviewed the manuscript.

\section{Acknowledgements}

Not applicable

\section{Authors' information}

Author unit: Shanghai University of Engineering Science, Shanghai 201600 About the author: Duan Yajun (1998-), female, Taiyuan, Shanxi, a postgraduate student at the School of Management, Shanghai University of Engineering Science; Luo Juan (1984-), female, Wuhan, Hubei, associate professor, Shanghai University of Engineering Science, Shanghai Research Center for Social Security Issues Deputy Director, PhD

Corresponding author: Luo Juan, emmaluojuan@163.com 


\section{References}

[1] WHO Regional Office for Europe. "Health of older refugees and migrants", November 20, http://www.euro.who.int/pubreq.

[2] Jane M. Cramm and Anna P. Nieboer. Aging perceptions matter for the well-being of elderly Turkish migrants, especially among the chronically ill[J]. 2018, 18(1) : 229. [3] Laura Corneliusson et al. Residing in sheltered housing versus ageing in place Population characteristics, health status and social participation[J]. Health \& Social Care in the Community, 2019, 27(4) : e313-e322.

[4] G.J. Walkden et al. Frailty in older-age European migrants: Cross-sectional and longitudinal analyses of the Survey of Health, Aging and Retirement in Europe (SHARE)[J]. Social Science \& Medicine, 2018, $213: 1-11$.

[5] Thomas D. Brothers and Olga Theou and Kenneth Rockwood. Frailty and migration in middle-aged and older Europeans[J]. Archives of Gerontology and Geriatrics, 2014, 58(1) : 63-68.

[6] Xie Jin, Zhu Qing, Wang Xiaokun. Research on the Health Influencing Factors of the Floating Elderly Population in my country[J]. Urban Development Research, 2020, 27(11): 30-35.

[7] Wu Yu, Fang Zhi, Liu Aihua. The health and influencing factors of the elderly floating population from the dual perspective of "age-mobility"__ Based on the data of the national floating population health and family planning dynamic monitoring survey in 2017[J]. Lanzhou Academic Journal, 2020(01) ): 157-171.

[8] Liu Tingting, Li Hanwei, Gao Kai. Analysis of housing choices and influencing factors of floating population with family migration: Taking Shanghai as an example [J]. Southern Population, 2014, 29(03): 17-27.

[9]Zhou Qingjie. The dual nature of self-owned housing and its treatment in CPI[J]. Economic Theory and Economic Management, 2008(03): 21-25.

[10]Jia Cangcang, He Weiwei. The impact of child care on the health of the elderly: counterfactual estimation based on propensity score matching (PSM) [J]. Ningxia Social Sciences, 2020(06): 125-135.

[11] Xia Cuicui, Li Jianxin. Healthy aging or painful aging: the chronic disease of the elderly population from the perspective of a healthy China strategy[J]. Exploration 
and Controversy, 2018(10): 115-121+144.

[12]Hou Huili, Li Chunhua. Identity, Region and City: Inequality of Basic Public Health Services for the Elderly Floating Population[J]. Population and Development, 2019, 25(02): 31-38.

[13]He Yuanzhuo, Shi Hong, He Nanfu, Li Xiangrong, Ren Zheng, Fan Xinwen, Guo Xia, Zha Shuang, Qiao Shuyin, Zhao Hanfang, Zhang Xiumin. Utilization and influencing factors of health management services for patients with chronic diseases in the middle-aged and elderly floating population in the three eastern provinces[ $\mathrm{J}$ ). Chinese Journal of Gerontology, 2021,41(06):1330-1332.

[14]Guo Jing, Xue Liping, Fan Hui. Self-rated health status and influencing factors of the floating elderly population. Ordered logistic regression analysis [J]. Chinese Public Health, 2017, 33(12): 1697-1700.

[15]Li Hui, Wang Liangjian. Housing prices, housing price-to-income ratios and the long-term residence willingness of the floating population: micro-evidence from the floating population[J]. Economic Geography, 2019, 39(06): 86-96.

[16]Jiang Xiangqun, Wei Meng, Zhang Wenjuan. Research on the health status and influencing factors of the elderly population in China[J]. Journal of Demography, 2015, 37(02): 46-56.

[17]Jin Yongai, Zhou Feng, Zhai Zhenwu. The influence of living style on the mental health of the elderly-the moderating effect of the community environment[J]. Journal of Demography, 2017, 39(03): 66-77.

[18]Liu Houlian. Analysis of the housing situation of the floating population in my country's megacities[J]. Journal of Demography, 2016, 38(05): 45-53.

[19]Zuo Ting, Wang Lili. Public rental housing construction in my country's central cities under the background of population flow[J]. Chinese Administration, 2011 (06): 28-31.

[20]Wang Fangbing. Research on the living environment needs of the elderly living at home in the city[D]. East China Normal University, 2015. 